\title{
ОЦЕНКА БИОХИМИЧЕСКИХ ПОКАЗАТЕЛЕЙ КРОВИ И ПОЧЕЧНОЙ ДИСФУНКЦИИ У БОЛЬНЫХ С ХРОНИЧЕСКОЙ СЕРДЕЧНОЙ НЕДОСТАТОЧНОСТЬЮ
}

Вступление. Почечная дисфункция - основная причина распространения значимых сопутствующих состояний, ассоциированных с неблагоприятным клиническим прогнозом. Необходимо отметить, что хроническая сердечная недостаточность резко ухудшает качество жизни пациентов, а также увеличивает риск летальности. Уровень летальности в течение года составляет 15-50 \%. Основным фрактором ухудшения почечной фрункции является понижение сердечного выброса и венозного застоя. В связи с понижением сердечного выброса уменьшается почечная перфузия и, таким образом, скорость клубочковой фрильтрации. Венозный застой относится к причинам повышения давления в выносящих артериолах и капиллярах клубочков.

Цель исследования - изучить показатели дисфункции почек у больных с хронической сердечной недостаточностью.

Методы исследования. Обследовано 96 больных с постинфарктным кардиосклерозом, осложненным хронической сердечной недостаточностью, в возрасте 40-60 лет. Их разделили на 2 группы по фрункциональному классу хронической сердечной недостаточности согласно классификации Нью-Йоркской ассоциации сердца (NYHA). У всех пациентов определяли уровень креатинина, по фрормуле MDRD (Modlflcatlon of Diet In Renal Disease Study) вычисляли скорость клубочковой фрильтрации. Спектрофотометричеким методом в моче определяли фрерменты: аланинаминотрансфреразу, аспартатаминотрансферазу, щелочную фросоратазу, холинэстеразу.

Результаты и обсуждение. У 33,3 \% больных со I/ фрункциональным классом хронической сердечной недостаточности и у 66,7 \% пациентов с III фрункциональным классом хронической сердечной недостаточности скорость клубочковой фильтрации была <60 мл/мин/1,73 м². Во время изучения показателей фрерментурии у больных с хронической сердечной недостаточностью в зависимости от фрункционального состояния почек выявлено, что у пациентов со скоростью клубочковой фрильтрации <60 мл/мин/1,73 м², среди которых больные с III фрункциональным классом хронической сердечной недостаточности составляли 66,7 \%, отмечали достоверно высокие показатели фрерментурии. При этом уровень аланинаминотрансфреразы был на 39 \% (p<0,01), щелочной фоосфратазы - на 35 \% $(p<0,001)$ выше по сравнению с показателями больных без нарушения фрункции почек.

Выводы. У пациентов с хронической сердечной недостаточностью по мере прогрессирования заболевания отмечают субклиническое нарушение фрункции почек, характеризующееся уменьшением скорости клубочковой фрильтрации, повышением уровня остаточного азота и фрерментурии. Определение уровня фрерментов в моче больных с хронической сердечной недостаточностью можно рассматривать как диагностический подход к ранней диагностике дисфункции почек.

КЛЮЧЕВЫЕ СЛОВА: хроническая сердечная недостаточность; дисфункция почек; креатинин; скорость клубочковой фильтрации; ферментурия.

ВСТУПЛЕНИЕ. Хроническая сердечная недостаточность (XCH) является одной из самых распространенных, прогрессирующих и прогностических неблагоприятных патологий сердечно-сосудистой системы, а также одной из наиболее частых причин госпитализаций. По данным Фремингемского исследования, частота ХCH удваивается каждое десятилетие. Хроническая сердечная недостаточность резко ухуд(с) М. Э. Рахимова, Р. И. Туракулов, Ф. Ш. Кадирова, А. А. Мирбайзаев, Р. К. Корахонов, Ж. Д. Худайбердиева, 2020. шает качество жизни больных и в 4 раза повышает риск смерти; уровень смертности больных в течение года составляет 15-50\%. Риск внезапной смерти у пациентов с ХCH в 5 раз превышает показатель у лиц без ХCH [1, 2]. В настоящее время широко обсуждается проблема кардиоренального синдрома у больных с XCH $[3,4]$. Доказано взаимное негативное влияние диссрункции почек и сердца, выражающееся в прогрессировании почечной диссрункции при нарастании ХCH и ухудшении фрункции сердца 
в случае прогрессирования почечной недостаточности $[5,6]$.

Результаты исследований ACCoMPliSH (Avoidlng Cardiovascular events through Combination therapy in Patients Living with Systolic Hypertension), SHARP (Subcutaneous Heparin and Angioplasty Restenosis), RoADMAP (Randomised Olmesartan And Diabetes Microalbuminuria), CARReSS-Hf (Cardiorenal Rescue Study In acute decompensated Heart Failure) и некоторых других позволили признать хроническую болезнь почек независимым фрактором риска развития сердечно-сосудистых заболеваний и ишемической болезни сердца по риску осложнений и легли в основу современных международных рекомендаций [7-9]. Ряд исследований доказал, что даже самые ранние субклинические нарушения функции почек являются независимыми факторами риска сердечно-сосудистых осложнений и смерти, а также повторных осложнений у пациентов с сердечно-сосудистыми заболеваниями. Показано, что при ХCH уровень креатинина (Кр), аналогично фракции выброса левого желудочка (ФВ ЛЖ), - независимый предиктор неблагоприятного прогноза. Установлено, что у больных с XCH наличие почечной дисфункции является предиктором неблагоприятного клинического прогноза, даже более значимым, чем тяжесть сердечной недостаточности и фрракция выброса левого желудочка [10]. Распространенность нарушения функции почек при ХCH, по данным различных исследований, колеблется от 25 до 60 \%. Аналогично ФВ ЛЖ, при ХСН уменьшение скорости клубочковой фильтрации (СКФ) и уровень Кр рассматривают в качестве независимых признаков неблагоприятного прогноза. При СКФ <60 мл/мин/1,73 м² риск смертности увеличивается в 2,1 раза, в случае сниженной систолической функции левого желудочка риск смерти пациентов при наличии почечной недостаточности возрастает в 3,8 раза, при неизмененной систолической фрункции - в 2,9 раза. Вовремяпроведения многочисленныхэпидемиологических, проспективных, ретроспективных, клинических исследований была установлена тесная ассоциация между тяжестью почечной диссрункции, оцениваемой по величине редукции СКФ/концентрации Кр плазмы крови, и риском общей смерти, а также возникновением различных сердечно-сосудистых событий [11-13].

Цель исследования - изучить показатели дисфункции почек у больных с хронической сердечной недостаточностью.

МЕТОДЫ ИССЛЕДОВАНИЯ. ОбслеДовано 96 больных с постинфрарктным кардиосклерозом, осложненным ХCH, в возрасте 40-60 лет.
Их разделили на 2 группы по фрункциональному классу (ФК) ХСН согласно классификации НьюЙоркской ассоциации сердца (NYHA) по данным проведения теста 6-минутной ходьбы (6-мх) и шкале оценки клинического состояния больных (ШОКС). В 1-ю группу вошел 51 больной со II ФК XCH, 2-ю группу составили 44 пациента с III ФК ХСН. В группу контроля (ГК) вошли 20 здоровых добровольцев. В исследовании не участвовали больные сахарным диабетом. У всех пациентов определяли уровень Кр, по формуле MDRD (Modlflcatlon of Diet In Renal Disease Study) вычисляли СКФ. Спектрофротометрическим методом в моче определяли фрерменты: аланинаминотрансфреразу (АлАТ), аспартатаминотрансфреразу (АсАТ), щелочную фроссратазу (ЩФ), холинэстеразу (ХЭ).

Статистическую обработку результатов исследования проводили на персональном компьютере типа IBMPC/AT с использованием пакета электронных таблиц Microsoft Excel (EXCel) 6.0. Параметры описывали в виде: среднее арифметическое \pm стандартное откло-

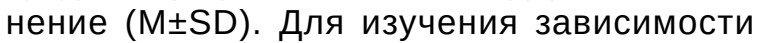
между количественными переменными применяли корреляционный анализ с вычислением коэффрициента линейной корреляции Пирсона или коэфффициента ранговой корреляции Спирмена. Различия считали значимыми при уровне значимости $p<0,05$.

РЕЗУЛЬТАТЫ И ОБСУЖДЕНИЕ. АНаЛИЗ результатов исследования показал, что у больных со II ФК ХСН показатель Кр составил $(109,4 \pm 8,9)$ ммоль/л, что на 24,85 \% выше показателя в ГК $(p<0,05)$. У пациентов c III ФК XCH данный показатель превышал значения в ГК на $40,3 \%$, составляя $(125,4 \pm 6,8)$ ммоль/л $(p<0,001)$. Исходные параметры СКФ составили $(76,4 \pm 19,1)$ мл/мин/1,73 м² у больных со ІІ ФК $\mathrm{XCH} \mathrm{и}(66,3 \pm 12,8)$ мл/мин/1,73 м² у пациентов с III ФК ХСН соответственно. Уровень остаточного азота у больных с II и ІІІ ФК ХСН был на 59,4 \% $(p<0,05)$ и $85 \%(p<0,01)$ выше по сравнению c показателями ГК, составляя $(30,08 \pm 2,57)$ и $(34,87 \pm 2,49)$ моль/л, $(18,9 \pm 0,4)$ моль/л соответственно.

При этом СКФ <60 мл/мин/1,73 м² отмечали у 33,3 \% больных со II ФК ХСН и у 66,7 \% пациентов с III ФК ХСН (табл. 1). Уровень Кр у больных с СКФ $\geq 60$ мл/мин/1,73 м² составил $(89,5 \pm 9,2)$ ммоль/л, тогда как у пациентов с СКФ $<60$ мл/мин/1,73 м² - $(123,9 \pm 12,1)$ ммоль/л ( $<<0,001)$. Изучение показателей толерантности к физической нагрузке, по результатам теста 6-мх в зависимости от функционального состояния почек, показало, что у больных с СКФ 
$\geq 60$ мл/мин/1,73 м² данный показатель составил $(344,6 \pm 21,8)$ м, а у пациентов с СКФ $<60$ мл/мин/1,73 м² - $(235,0 \pm 8,2)$ м. Показатель шОКС у больных с XCH также характеризовал более тяжелое клиническое течение заболевания у пациентов с СКФ <60 мл/мин/1,73 м² $(8,1 \pm 0,6)$ балла, убольныхсСКФ $\geq 60$ мл/мин/1,73 м² он составил $(5,6 \pm 0,5)$ балла.

Анализ фрерментурии у больных с XCH показал, что у пациентов со II ФК XСН достоверно увеличивался уровень ферментов в моче: АлАТ - на 50,9 \%, АсАТ - на 39,4 \%, ЩФ - на $82,5 \%$, ХЭ - на 38,7 \% $(\mathrm{p}<0,05)$ по сравнению с ГК (табл. 2). У больных с ІІІ ФК ХСН показатели срерментурии составили: АлАТ - $(4,68 \pm 0,13)$ ед./л, АсАТ - $(4,13 \pm 0,12)$ ед./л, ЩФ - $(1,86 \pm 0,08)$ ед./л и ХЭ- $(90,79 \pm 3,44)$ ед./л, что на $85,0 \%$ ( $p<0,001)$, $53,5 \%(p<0,05), 129,6 \%(p<0,001)$ и $52,3 \%$ $(p<0,001)$, соответственно, выше по сравнению с показателями здоровых лиц. Результаты исследования показали, что у пациентов с XСH как со II, так и с III ФК достоверно увеличивались показатели фрерментурии.
У больныХ с III ФК ХСН увеличение показателей АлАТ и АсАТ составило 1,8 и 1,5 раз, что, соответственно, выше показателей ГК, это указывает на глубокие повреждения в цитоплазматических мембранах тубулярного эпителия. Рост показателя ЩФ у пациентов с III ФК XСН, по сравнению со II ФК, составил 25,7%. Во время изучения показателей ферментурии у больных с ХCH в зависимости от функционального состояния почек выявлено, что у пациентов с СКФ $<60$ мл/мин/1,73 м², среди которых больные с III ФК ХСН составляли 66,7 \%, отмечали достоверно высокие показатели ферментурии. При этом уровень АлАТ был на $39 \%$ ( $<<0,01)$, ЩФ на $35 \%(p<0,001)$ выше по сравнению с показателями больных без нарушения фрункции почек (табл. 3).

Результаты исследования показали, что у пациентов с XCH по мере прогрессирования заболевания отмечают субклиническое нарушение срункции почек, характеризующееся уменьшением СКФ, повышением уровня остаточного азота [14] и фрерментурии.

Таблица 1 - Характеристика больных с хронической сердечной недостаточностью в зависимости от функционального состояния почек (M $\pm S D$ )

\begin{tabular}{|c|c|c|}
\hline Показатель & $\begin{array}{c}\text { Больные с СКФ } \geq 60 \text { мл/мин/1,73 м² } \\
(n=41)\end{array}$ & $\begin{array}{c}\text { Больные с СКФ <60 мл/мин/1,73 м² } \\
(\mathrm{n}=27)\end{array}$ \\
\hline Возраст, лет & $53,4 \pm 6,2$ & $55,3 \pm 4,8$ \\
\hline$\Phi \mathrm{KCCH}$ & & \\
\hline II & $35(68,7 \%)$ & $16(31,3 \%)$ \\
\hline III & $16(36,4 \%)$ & $28(63,6 \%)$ \\
\hline 6-MX, M & $344,6 \pm 21,8$ & $237,5 \pm 9,4$ \\
\hline ШОКС & $5,6 \pm 0,5$ & $\begin{array}{c}8,1 \pm 0,6 \\
(p<0,001)\end{array}$ \\
\hline ФВ ЛЖ, \% & $49,4 \pm 1,8$ & $44,6 \pm 2,5$ \\
\hline Кр, мкмоль/л & $88,8 \pm 8,4$ & $\begin{array}{c}124,6 \pm 11,3 \\
(p<0,001)\end{array}$ \\
\hline СКФ, мл/мин/1,73 м² & $75,3 \pm 11,7$ & $\begin{array}{l}54,6 \pm 5,3 \\
(p<0,001)\end{array}$ \\
\hline
\end{tabular}

Таблица 2 - Показатели ферментурии у больных с хронической сердечной

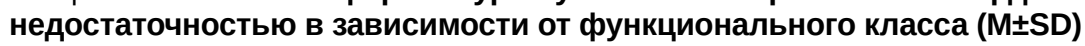

\begin{tabular}{||l|c|c|c|}
\hline \multicolumn{1}{|c|}{ Показатель } & Группа контроля & $\begin{array}{c}\text { 1-я группа } \\
\text { II ФК }(\mathrm{n}=36)\end{array}$ & $\begin{array}{c}\text { 2-я группа } \\
\text { III ФК }(\mathrm{n}=32)\end{array}$ \\
\hline АлАТ, ед./л & $2,53 \pm 0,02$ & $3,82 \pm 0,15$ & $4,68 \pm 0,13$ \\
\hline АсАТ, ед./л & $2,69 \pm 0,02$ & $3,75 \pm 0,11$ & $4,13 \pm 0,12$ \\
\hline Щ, ед./л & $0,81 \pm 0,01$ & $1,48 \pm 0,12$ & $1,86 \pm 0,08$ \\
\hline ХЭ, ед./л & $59,63 \pm 2,82$ & $82,69 \pm 3,21$ & $90,79 \pm 3,44$ \\
\hline
\end{tabular}

Таблица 3 - Показатели ферментурии у больных с хронической сердечной

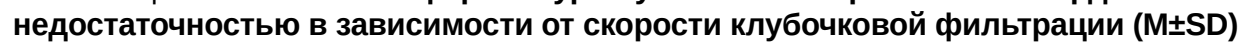

\begin{tabular}{|c|c|c|}
\hline Показатель & $\begin{array}{c}\text { Больные с СКФ } \geq 60 \text { мл/мин/1,73 м² } \\
\qquad(\mathrm{n}=41)\end{array}$ & $\begin{array}{c}\text { Больные с СКФ }<60 \text { мл/мин/1,73 м² } \\
\text { (n=27) }\end{array}$ \\
\hline АлАТ, ед./л & $3,32 \pm 0,23$ & $4,62 \pm 0,15$ \\
\hline АсАТ, ед./л & $3,56 \pm 0,19$ & $4,25 \pm 0,11$ \\
\hline ЩФ, ед./л & $1,42 \pm 0,09$ & $1,92 \pm 0,13$ \\
\hline ХЭ, ед./Л & $78,45 \pm 4,33$ & $87,54 \pm 4,23$ \\
\hline
\end{tabular}


Известно, что исследуемые трансаминазы АлАТ и АсАТ локализованы преимущественно в эпителиальных клетках проксимального отдела канальцевого аппарата нефрона, и они не фрильтруются через базальную мембрану клубочков нефрронов. Заметный прирост АлАТ и АсАТ у больных с ХСН свидетельствует о глубоких повреждениях цитоплазматических мембран тубулярного эпителия с выходом в просвет канальцев компонентов цитозоля. Для изучения состояния гломерулярного фильтра можно определять активность в моче фрермента ХЭ. У пациентов с XCH и диссрункцией почек наблюдали выраженный прирост данного показателя. Это подтверждается и увеличением уровня ЩФ, особенно у больных с выраженной диссуннцией почек, так как фрермент ЩФ связан с щеточной каемкой и цитоплазматической мембраной тубулярного эпителия почечных канальцев [15]. В связи с вышеизложенным, определять активность ЩФ в моче можно для оценки степени повреждения поверхностных структур цитомембран. Определение уровня фрерментов в моче

СПИСОК ЛИТЕРАТУРЫ

1. To die with of from heart failure: a difference that counts: is heart failure underrepresented in national mortality statistics? / P. M. Engelfriet, R. T. Hoogenveen, H. C. Boshuizen [et al.] // Eur. J. Heart Fail. - 2011. 13. - P. 37-38.

2. Long term prognosis of chronic heart failure: reduced vs preserved left ventricular ejection fraction / K. Miyagishima, S. Hiramitsu, H. Kimura [et al.] // Circulation. - 2009. - 73 (1). - P. 92-99.

3. Arutunov G. P. Pathophysiological processes in kidneys of patients with CHF / G. P. Arutunov // J. Heart Faiu. - 2008. - 9 (5). - P. 234-249.

4. Bock J. S. Cardiorenal syndrome: new perspecti ves / J. S. Bock, S. S. Gottlieb // Circulation. - 2010. 21. $-2592 \mathrm{p}$.

5. Berl T. Kidney-heart interactions: Epidemiology, pathogenesis, and treatment / T. Berl, W. Henrich // Clin. J. Am. Soc. Nephrol. - 2006. - 1. - P. 8-18.

6. Chronic kidney disease: Implications for the perioperative period / H. Eilers, K. D. Liu, A. Gruber, C. U. Niemann // Minerva Anestesiol. - 2010. - 76 (9). - P. 725736.

7. ACCOMPLISH Trial Investigators. Renal outcomes with different fixed-dose combination therapies in $p$ atients with hypertension at high risk for cardiovascular events (ACCOMPLISH): a prespecified secondary analysis of randomised controlled trial / G. L. Bakris, P. A. Serafidis, M. R. Weir [et al.] // Lancet. - 2010. - 375. P. 1173-1181. больных с ХCH можно рассматривать как диагностический подход к ранней диагностике дисфрунции почек.

Анализ полученных данных показал прямую корреляционную зависимость между повышением уровня орерментов в моче и Кр в крови средней степени $(r=0,49)$, и имеется отрицательная сильная корреляция $(r=-0,71)$ между СКФ и уровнем фрерментов в моче.

ВЫВОДЫ. У больных со II и III ФК ХCH, наряду с увеличением уровня Кр, уменьшением СКФ, наблюдают нарушения со стороны тубулоэпителиальной системы почек, характеризующиеся фрерментурией. У пациентов с ХСH фрерментурия усиливается по мере прогрессирования заболевания и дисфункции почек. Ферментурия у больных с ХСН свидетельствует о наличии нарушений со стороны тубулоэпителиальной системы почек на начальных стадиях их дисфункции, что дает возможность рассматривать определение ферментурии при ХCH в качестве раннего маркера оценки функционального состояния почек.

8. KDIGO 2012 Clinical Practice Guideline for the Evaluation and Management of Chronic Kidney Disease // Kidney Int. (Suppl.) - 2013. - 3. - P. 1-150.

9. National Kidney Foundation's Kidney Early Evaluation Program (KEEP) Annual Data Report 2011: Executive Summary / A. T. Whaley-Connell, J. A. Vassalotti, A. J. Collins [et al.] // Am. J. Kidney Dis. -2012. 59 (3), (Suppl. 2). - S. 1-4.

10. Cardiorenal syndrome: A literature review / N. Pokhrel, N. Maharjan, B. Dhakal [et al.] // Exp. Clin. Cardiol. - 2008. - 13 (4). - P. 165-170.

11. Renal function and prediction of cardiovascular risk // Cardiovascular Therapy and Prevention. - 2008. 7 (6). - Appendix 3.

12. Renal function in heart failure: a disparity between estimating function and predicting mortality risk / M. Plischke, S. Neuhold, M. Kohl [et al.] // Eur. J. Heart Failure. - 2013. - 15 (7). - P. 763-770.

13. The cardiorenal syndrome / C. Ronco, C. Y. Chionh, M. Haapio [et al.] // Blood Purif. - 2009. 27 (1). - P. 114-126.

14. Mavlyanov I. R. The renal tubular epithelial system in patients with rheumatoid arthritis in relation to its duration / I. R. Mavlyanov, G. P. Akbarova, N. L. Khabilova // Profilac Medicine. - 2009. - 3. - P. 14-9.

15. Cardiorenal syndrome: biomarkers linking kidney damage with heart failure / S. Soni, Y. Fahuan, C. Ronco [et al.] // Biomarkers Med. - 2009. - 3 (5). - P. 549-560. 


\section{REFERENCES}

1. Engelfriet, P.M., Hoogenveen, R.T., \& Boshuizen, H.C. (2011). To die with of from heart failure: a difference that counts: is heart failure underrepresented in national mortality statistics? Eur. J. Heart Fail., (13), 3738.

2. Miyagishima, K., Hiramitsu, S., \& Kimura, H. (2009). Long term prognosis of chronic heart failure: reduced vs preserved left ventricular ejection fraction. Circulation, 73 (1), 92-99.

3. Arutunov, G.P. Pathophysiological processes in kidneys of patients with CHF. J. Heart Faiu, 9 (5), 234249.

4. Bock, J.S., \& Gottlieb, S.S. (2010). Cardiorenal s yndrome: new perspectives. Circulation, 21, 2592.

5. Berl, T., \& Henrich, W. Kidney-heart interactions: Epidemiology, pathogenesis, and treatment. Clin. J. Am. Soc. Nephrol., 1, 8-18.

6. Eilers, H., Liu, K.D., Gruber, A., \& Niemann, C.U. (2010). Chronic kidney disease: Implications for the perioperative period. Minerva Anestesiol., 76 (9), 725736.

7. Bakris, G.L., Serafidis, P.A., \& Weir, M.R. ACCOMPLISH Trial Investigators. Renal outcomes with different fixed-dose combination therapies in patients $\mathrm{w}$ ith hypertension at high risk for cardiovascular events (ACCOMPLISH): a prespecified secondary analysis of randomised controlled trial. Lancet, 375, 1173-1181.
8. (2013). KDIGO 2012 Clinical Practice Guideline for the Evaluation and Management of Chronic Kidney Disease. Kidney Int., 3, 1-150.

9. Whaley-Connell, A.T., Vassalotti, J.A., \& Collins, A.J. (2012). National Kidney Foundation's Kidney Early Evaluation Program (KEEP) Annual Data Report 2011: Executive Summary. Am. J. Kidney Dis., 59 (3) (Suppl. 2), S1-4.

10. Pokhrel, N., Maharjan, N., \& Dhakal, B. (2008). Cardiorenal syndrome: A literature review. Exp. Clin. Cardiol., 13 (4), 165-170.

11. (2008). Renal function and prediction of cardiovascular risk. Cardiovascular Therapy and Prevention, 7 (6), Appendix 3.

12. Plischke, M., Neuhold, S., \& Kohl, M. (2013). Renal function in heart failure: a disparity between estimating function and predicting mortality risk. Eur. J. Heart Failure, 15 (7), 763-770.

13. Ronco, C., Chionh, C.Y., \& Haapio, M. (2009). The cardiorenal syndrome. Blood Purif., 27 (1), 114-126.

14. Mavlyanov, I.R., Akbarova, G.P., \& Khabilova, N.L. (2009). The renal tubular epithelial system in patients with rheumatoid arthritis in relation to its duration. Profilac. Medicine, 3, 14-19.

15. Soni, S., Fahuan, Y., \& Ronco, C. (2009). Cardiorenal syndrome: biomarkers linking kidney damage with heart failure. Biomarkers Med., 3 (5), 549-560.

М. Е. Рахімова, Р. І. Туракулов, Ф. Ш. Кадірова, А. А. Мірбайзаєв, Р. К. Корахонов, Ж. Д. Худайбердієва ТАШКЕНТСЬКА МЕДИЧНА АКАДЕМІЯ

\section{ОЦІНКА БІОХІМІЧНИХ ПОКАЗНИКІВ КРОВІ Й НИРКОВОЇ ДИСФУНКЦІЇ У ХВОРИХ ІЗ ХРОНІЧНОЮ СЕРЦЕВОЮ НЕДОСТАТНІСТЮ}

\section{Резюме}

Вступ. Ниркова диссуннція - основна причина поширення значущих супутніх станів, асоційованих 3 несприятливим клінічним прогнозом. Необхідно відзначити, що хронічна серцева недостатність різко погіршує якість життя пацієнтів, а також збільшує ризик летальності. Рівень летальності протягом року становить 15-50 \%. Основним чинником погіршення ниркової функції є зниження серцевого викиду і венозного застою. У зв'язку зі зниженням серцевого викиду зменшується ниркова пероузія $i$, таким чином, швидкість клубочкової фрільтрації. Венозний застій спричиняє підвищення тиску у виносних артеріолах $і$ капілярах клубочків.

Мета дослідження - вивчити показники дисфункції нирок у хворих із хронічною серцевою недостатністю.

Методи дослідження. Обстежено 96 хворих з постінфрарктним кардіосклерозом, ускладненим хронічною серцевою недостатністю, віком 40-60 років. їх поділили на 2 групи за функціональним класом хронічної серцевої недостатності здідно з класифікацією Нью-Йоркської асоціації серця (NYHA). У всіх пацієнтів визначали рівень креатиніну, за фрормулою MDRD (Modlflcatlon of Diet In Renal Disease Study) обчислювали швидкість клубочкової фрільтрації. Спектрофротометричним методом у сечі визначали ензими: аланінамінотрансферазу, аспартатамінотрансфреразу, лужну фросфратазу, холінестеразу.

Результати й обговорення. У 33,3 \% хворих з ІІ фрункціональним класом хронічної серцевої недостатності й у 66,7\% пацієнтів з III функціональним класом хронічної серцевої недостатності швидкість клубочкової фрільтрації була <60 мл/хв/1,73 м². Під час вивчення показників фрерментурії у хворих із хронічною серцевою недостатністю залежно від функціонального стану нирок виявлено, що у пацієнтів зі швидкістю клубочкової фрільтрації <60 мл/хв/1,73 м², серед яких хворі з III фрункціональним класом хронічної серцевої недостатності становили 66,7 \%, відзначали достовірно високі показники ферментурії. При цьому рівень аланінамінотрансфрерази був на $39 \%(p<0,01)$, лужної фросфратази - на $35 \%(p<0,001)$ вищий порівняно 3 показниками хворих без порушення фуункції нирок. 
Висновки. У пацієнтів із хронічною серцевою недостатністю в міру прогресування захворювання відзначають субклінічне порушення фрункції нирок, що характеризується зменшенням швидкості клубочкової фрільтрації, підвищенням рівня залишкового азоту і фрерментурії. Визначення рівня ензимів у сечі хворих із хронічною серцевою недостатністю можна розглядати як діагностичний підхід до ранньої діагностики диссрункції нирок.

КЛЮЧОВІ СЛОВА: хронічна серцева недостатність; дисфункція нирок; креатинін; швидкість клубочкової фрільтрації; фрерментурія.

M. E. Rakhimova, R. I. Turakulov, F. Sh. Kadirova, A. A. Mirbayzaev, R. K. Korakhonov, J. D. Xudayberdieva TASHKENT MEDICAL ACADEMY

\title{
EVALUATION OF BIOCHEMICAL PARAMETERS OF BLOOD AND RENAL DYSFUNCTION IN PATIENTS WITH CHRONIC HEART FAILURE
}

\begin{abstract}
Summary
Introduction. Renal dysfunction is the leading cause of significant comorbidities associated with an unfavorable clinical prognosis. It should be noted that chronic heart failure dramatically impairs the quality of life of patients and increases the risk of mortality. The mortality rate during the year is 15-50\%. The main factor in the deterioration of renal function is a decrease in cardiac output and venous stasis. Decreased cardiac output decreases renal perfusion and thus glomerular filtration rate. Venous stasis causes an increase in pressure in the external arterioles and capillaries of the glomeruli.
\end{abstract}

The aim of the study - to learn the kidney dysfunction indices in patients with chronic heart failure (CHF).

Research Methods. 96 patients with postinfarction cardiosclerosis complicated by CHF at the age of 40-60 years were examined. Patients were divided into two groups by functional class (FC) of CHF according to the New York Heart Association (NYHA). The creatinine level was determined for all patients, and the glomerular filtration rate (GFR) was calculated using the formula MDRD (Modification of Diet in Renal Disease Study). Determination of enzymes in urine - alanine transferase (ALT), aspartate transferase (AST), alkaline phosphotase (ALK phos), cholinesterase by spectrophotometric method.

Results and Discussion. GFR $<60 \mathrm{ml} / \mathrm{min} / 1,73 \mathrm{~m} 2$ was marked in $33.3 \%$ of patients with II FC CHF and $66.7 \%$ of patients with III FC CHF. The study of fermentation indices in patients with CHF depending on the functional state of the kidneys revealed that in patients with GFR $<60 \mathrm{ml} / \mathrm{min} / 1,73 \mathrm{~m} 2$, among which the patients with III FC CHF were $66.7 \%$, reliably high fermentation indices were noted. At the same time, level of ALT was $39 \%(p<0.01)$ and $35 \%(p<0.001)$ higher in comparison with patients without kidney function impairment.

Conclusions. In CHF patients subclinical renal dysfunction has been observed in process of progression of the disease which is characterized by reduction of GFR, increase of residual nitrogen level and fermentation. Urinary enzyme level determination in patients with CHF can be considered as a diagnostic approach for early diagnosis of renal dysfunction.

KEY WORDS: chronic heart failure; kidney dysfunction; creatinine; glomerular filtration rate; fermentation.

Получено 21.08.20

Адресс для переписки: Ф. Ш. Кадирова, Ташкентская медицинская академия, Форобий 2, Ташкент, 100109, Узбекистан, e-mail: farzona.kadirova88@gmail.com., info@tma.uz. 